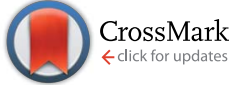

Cite this: RSC Adv., 2017, 7, 13010
Received 23rd January 2017 Accepted 17th February 2017

DOI: $10.1039 / \mathrm{c} 7 \mathrm{ra01008g}$

rsc.li/rsc-advances

\section{Oxidative stress-induced apoptosis of osteoblastic MC3T3-E1 cells by hydroxyapatite nanoparticles through lysosomal and mitochondrial pathways}

\author{
Yi Jin, ${ }^{\text {ab }}$ Xiaolong Liu, ${ }^{a}$ Huifang Liu, ${ }^{a}$ Shizhu Chen, ${ }^{a}$ Chunyue Gao, ${ }^{a}$ Kun Ge, ${ }^{a}$ \\ Cuimiao Zhang ${ }^{a}$ and Jinchao Zhang*a
}

Hydroxyapatite nanoparticles (HAPs) are increasingly utilized in biomedical fields including dental composites, bone tissue engineering and orthopedic implants due to its similar properties to bone minerals. With their widespread use, toxicological effects of HAPs have aroused people's close attention. However, the potential toxic effects of HAPs on bone cells are poorly understood. In our present work, the HAPs with aspect ratios of 4 were synthesized by a hydrothermal method and characterized by transmission electron microscopy (TEM), X-ray diffractometry (XRD), dynamic light scattering (DLS) and photoluminescence (PL). The cytotoxicity of HAPs on MC3T3-E1 cells and the relevant mechanisms were further studied. The results proved that HAPs could be uptaken into MC3T3-E1 cells via macropinocytosis-mediated endocytosis pathway, and mainly localized in lysosome. HAPs inhibited the cells proliferation in dose- and time-dependent manners. Results from annexin V-FITC/PI apoptosis assay showed that HAPs induced cell apoptosis significantly, and the mechanism of apoptosis was related to oxidative stress. HAPs induced ROS generation and antioxidant enzymes superoxide dismutase (SOD) and glutathion peroxidase (GSH-Px) decrease, which not only induced a lysosome-dependent damage pathway via lysosomal membrane permeabilization (LMP) and increased the release of cathepsins B, but also a mitochondria-dependent damage pathway via counter regulating expressions of bax and bcl-2, decrease of mitochondrial membrane potential (MMP), activation of caspase3. In addition, the ROS also caused DNA damage. In summary, HAPs induces apoptosis through oxidative stressinduced lysosomal and mitochondrial pathways. Our study will provide some valuable data for biomedical applications of HAPs in the future.

\section{Introduction}

Hydroxyapatite $\left(\mathrm{HA}, \mathrm{Ca}_{5}\left(\mathrm{PO}_{4}\right)_{3} \mathrm{OH}\right)$, as an important inorganic constituent of biological hard tissues, has been considered to play a critical role in various bone tissue regeneration and teeth after trauma. ${ }^{\mathbf{1 - 3}}$ With the development of nanotechnology, hydroxyapatite nanoparticles (HAPs) are widely used in biomedical fields due to their improved biocompatibility, nonimmunogenicity, high osteoinductivity and good bioactivity. ${ }^{4-6}$ It has been proved that HAPs may promote osteoblast adhesion, proliferation, alkaline phosphatase synthesis and cause more rapid repair of hard tissue damage. During the past 20 years, there is growing interest in the application of HAPs in bone tissue engineering, such as filling bone defects, coating materials, orthopedic implants and so on. For example, Bhuiyan

${ }^{a}$ Key Laboratory of Chemical Biology of Hebei Province, Key Laboratory of Medicinal Chemistry and Molecular Diagnosis of the Ministry of Education, College of Chemistry \& Environmental Science, Hebei University, Baoding 071002, P. R. China. E-mail: jczhang6970@163.com; Tel: +86-312-5079627

${ }^{b}$ College of Basic Medical Science, Hebei University, Baoding 071000, P. R. China et al. created a complex collagen and HAP-based biopolymer for a bone graft substitute. ${ }^{7}$ Curtin et al. developed non-aggregating collagen HAP scaffolds which were used as a gene delivery platform for stem cell-mediated bone formation. ${ }^{8}$ The above results indicated that HAPs could serve as an ideal candidate in the bone tissue engineering field. However, with increased biological applications of HAPs, the concerns about their potential toxic effects on humans have also increased.

In recent years, studies about biocompatibility of HAPs were successively reported. For example, Remya et al. evaluated the molecular toxicity of $50 \mathrm{~nm}$ HAPs using bone marrow mesenchymal stem (BMSCs), and concluded that the in-house synthesized HAPs were non-toxic/safe to BMSCs at the molecular level. ${ }^{9}$ We previously reported that defect-related luminescent hydroxyapatite could enhance osteogenic differentiation of BMSCs via an ATP-induced cAMP/PKA pathway. ${ }^{10}$ Doostmohammadi et al. confirmed that bone-derived HA were compatible with BMSCs and HAPs could be used for bone tissue engineering. ${ }^{11}$ Sun et al. used primary osteoblastic cells as model to detect the biocompatibility of different-sized HAPs, and found that larger HAPs had a good biocompatibility with 
primary osteoblastic cells while smaller-sized HAPs can both promote osteoclast activity and restrain osteoblasts activity, implying that size-dependent cytotoxicity of HAPs. ${ }^{12}$ Chen et al. verified that the surface charge of HAPs play an important role in cellular uptake, cell viability and proliferation of osteoblast MC3T3-E1 cells. ${ }^{13}$ Wang et al. studied the toxicity effect of HAPs on the major organs of SD rats and MC3T3-E1 cells in vitro, displayed that HAPs could induce cells apoptosis in liver and renal tissues, and inhibit the proliferation of MC3T3-E1 cells. ${ }^{\mathbf{1 4}}$ However, the potential toxic effects of HAPs on bone cells are not well-understood.

MC3T3-E1 is an osteoblast precursor cell line derived from mouse calvaria. ${ }^{15} \mathrm{~A}$ number of derivatives of this strain have been isolated to select for varying degrees of osteogenic capability, and widely used as model systems in bone tissue engineering. The purpose of this study was to assess whether and how HAPs can inhibit the proliferation and induce the apoptosis of MC3T3-E1 cells, hence providing an interesting view of the biological application of HAPs in future.

\section{Materials and methods}

\section{Materials}

MC3T3-E1 cells were purchased from the cell bank of Peking Union Medical College (Beijing, China). Dulbecco's modified eagle medium (DMEM) and fetal bovine serum (FBS) were purchased from Gibco (Grand Island, NY, USA). 3-[4,5Dimethylthiazole-2-yl]-2,5-diphenyl tetrazolium bromide (MTT), trypsin, benzylpenicillin, streptomycin, rhodamine 123 (RH123), 2',7'-dichloroflourescein diacetate (DCFH-DA), ethidium bromide (EB), chlorpromazine hydrochloride, nystatin, wortmannin, acridine orange (AO) were purchased from Sigma (St. Louis, MO, USA). Cathepsin B activity kit, annexin V-fluorescein isothiocyanate (FITC)/PI apoptosis kit, Revertaid first strand cDNA synthesis kit, Lyso-Tracker Red and Mito-Tracker Green were obtained from Thermo Scientific (Rockford, USA). Superoxide dismutase (SOD) and glutathion peroxidase (GSH-Px) detection kits were purchased from Nanjing Jiancheng Bioengineering Institute (Jiangsu, CHN). Ultra SYBR Mixture was obtained from CWBIOTECH (Beijing, CHN).

\section{Synthesis and characterization of HAPs}

The HAPs were synthesized using a facile hydrothermal process according to literature with some modifications. ${ }^{\mathbf{1 6}}$ Calcium nitrate $\left[\mathrm{Ca}\left(\mathrm{NO}_{3}\right)_{2} \cdot 4 \mathrm{H}_{2} \mathrm{O}\right](2 \mathrm{mmol})$, hexadecyltrimethylammonium bromide (CTAB) (0.2 g), and ammonia solution $(5 \mathrm{~mL})$ to adjust the $\mathrm{pH}$ value 9.0 were dissolved in deionized water $(20 \mathrm{~mL})$. Trisodium citrate $(2 \mathrm{mmol})$ and $\left(\mathrm{NH}_{4}\right)_{2} \mathrm{HPO}_{4}(1.2 \mathrm{mmol})$ were added to $10 \mathrm{~mL} \mathrm{H} \mathrm{H}_{2} \mathrm{O}$. Then, the above solutions were mixed, stirred for $20 \mathrm{~min}$, transferred into a Teflon bottle, sealed, and maintained at $180{ }^{\circ} \mathrm{C}$ for $24 \mathrm{~h}$. The precipitates were separated, washed by deionized water and ethanol, and dried in air at $75{ }^{\circ} \mathrm{C}$ for $12 \mathrm{~h}$ to obtain HAPs.

The HAPs were characterized by powder X-ray diffraction (XRD) using D8 Advance diffractometer (Bruker, Germany). The morphology of the samples was observed by JSM-7500F cold field transmission electron microscope (TEM) (Tecnai G2, $\mathrm{S}$-Twin, FEI). The photoluminescence (PL) measurement was performed on F-7000 spectrophotometer. The dynamic light scattering (DLS) was obtained on Delsa Nana C grainsize analyzer (Beckman, USA). All measurements were performed at room temperature.

\section{Cytotoxicity}

Cytotoxicity was determined by MTT assay as previously described. ${ }^{17}$ The MC3T3-E1 cells $\left(2 \times 10^{4}\right.$ cells per well) were seeded in 96-well plates, HAPs was added at final concentrations of $10,20,30$, and $40 \mu \mathrm{g} \mathrm{mL} \mathrm{m}^{-1}$. Cells without nanoparticles treatment were used as control, wells without cells were used as blanks. Cells were cultured for 24,48 , and $72 \mathrm{~h}, 10 \mu \mathrm{L}$ MTT $\left(5.0 \mathrm{mg} \mathrm{mL}{ }^{-1}\right)$ was added, and incubated at $37^{\circ} \mathrm{C}$ for $4 \mathrm{~h}$. Then the MTT medium was discarded and $100 \mu \mathrm{L}$ of DMSO was added. The optical density (OD) value was measured by a microplate spectrophotometer (MD VersaMax, USA) at $570 \mathrm{~nm}$. The viability (\%) was calculated using the following formula: $\left(\mathrm{OD}_{\text {treated }}-\mathrm{OD}_{\text {blank }}\right) /\left(\mathrm{OD}_{\text {control }}-\mathrm{OD}_{\text {blank }}\right) \times 100$.

\section{Annexin V-FITC/PI apoptosis assay}

The apoptosis of cells was detected using annexin V-FITC/PI double labeling method. ${ }^{18}$ Briefly, cells $\left(3 \times 10^{5}\right.$ cells per well $)$ were seeded in 6-well plates overnight. After the treatment of HAPs $\left(40 \mu \mathrm{g} \mathrm{mL}^{-1}\right)$ for $24 \mathrm{~h}$, cells were resuspended and mixed with annexin V-FITC and PI for $15 \mathrm{~min}$. The apoptosis of cells was analyzed by flow cytometer (FACSCalibur ${ }^{\mathrm{TM}}$, Becton Dickinson).

\section{Cellular uptake and endocytosis mechanism}

Cells $\left(3 \times 10^{5}\right.$ cells per well) were plated in 6-well plates. After treatment by HAPs suspension $\left(40 \mu \mathrm{g} \mathrm{mL}^{-1}\right)$ for $2,4,8$, and $12 \mathrm{~h}$. The uptake of HAPs into MC3T3-E1 was analyzed by flow cytometer.

For cell endocytosis mechanism, ${ }^{19}$ cells $\left(3 \times 10^{5}\right.$ cells per well) were pre-treated with different inhibitors of endocytosis (3.5 $\mu \mathrm{M}$ chlorpromazine hydrochloride, $1 \mathrm{mM}$ nystatin or $400 \mathrm{nM}$ wortmannin) for $30 \mathrm{~min}$ at $37^{\circ} \mathrm{C}$. In addition, the cells were cultured with HAPs at 4 and $37^{\circ} \mathrm{C}$ as negative and positive controls, respectively. The uptake of HAPs was analyzed using flow cytometer.

\section{Intracellular localization of HAPs}

The intracellular localization of HAPs in MC3T3-E1 cells was traced with the Lyso-Tracker Red or Mito-Tracker Green, respectively. ${ }^{20}$ After cells were treated with HAPs $\left(40 \mu \mathrm{g} \mathrm{mL}{ }^{-1}\right)$ for $4 \mathrm{~h}$, Lyso-Tracker Red or Mito-Tracker Green was added. The images of cells were observed with a laser confocal scanning microscope (Olympus, IX81, Japan).

\section{Intracellular ROS measurement assay}

Intracellular ROS level was detected as previous literature. ${ }^{21}$ Cells $\left(6 \times 10^{5}\right.$ cells per well $)$ were seeded in 6 -well plates. After treatment of HAPs for $24 \mathrm{~h}$, the cells were stained with $5 \mu \mathrm{M}$ 
DCFH-DA and incubated at $37{ }^{\circ} \mathrm{C}$ for $30 \mathrm{~min}$. The fluorescence of oxidized DCF was detected by flow cytometer. In addition, the ROS level was also observed by morphology. After the same treatment as describe above, the cells' images were captured using a fluorescent microscopy (Olympus, IX53, Japan).

\section{SOD and GSH-Px measurement assays}

Cells were seeded in 6 -well plates at $6 \times 10^{5}$ cells per well. Following treatment by different concentrations of HAPs for $24 \mathrm{~h}$, the SOD, GSH-Px activities and protein content were measured by using SOD, GSH-Px and a micro-Bradford assay kits according to the manufacturer's instruction.

\section{Lysosomal membrane permeabilization (LMP) and cathepsin $B$ activity assay}

The LMP was measured by using AO relocation assay. ${ }^{22}$ Briefly, cells $\left(6 \times 10^{5}\right.$ cells per well) were seeded in 6 -well culture plates and incubated in the presence or absence of HAPs $\left(40 \mu \mathrm{g} \mathrm{mL}^{-1}\right)$ for $24 \mathrm{~h}$. Subsequently the cells were trypsinized and resuspended in PBS with $5 \mu \mathrm{g} \mathrm{mL} \mathrm{mL}^{-1}$ AO for $15 \mathrm{~min}$ at room temperature, then the red fluorescence was analyzed by flow cytometer.

For cathepsin B activity assay, cells $\left(6 \times 10^{5}\right.$ cells per well $)$ were seeded in 48-well culture plates and incubated with HAPs $\left(40 \mu \mathrm{g} \mathrm{mL}^{-1}\right)$ for $24 \mathrm{~h}$. The activity of cathepsin B was measured according to the manufacturer's instruction.

\section{Mitochondrial membrane potential (MMP) measurement assay}

The MMP was determined by the rhodamine 123 (RH123) staining. ${ }^{23}$ Cells $\left(6 \times 10^{5}\right.$ cells per well) were seeded into 6-well plates and treated with $10,20,30$, and $40 \mu \mathrm{g} \mathrm{mL}^{-1}$ of HAPs for $24 \mathrm{~h}$. Then, cells were stained with $10 \mathrm{mM}$ RH123. The fluorescence intensity of RH123 was analyzed by a flow cytometer.

\section{Caspase 3 and bax/bcl-2 gene expression}

After cells were treated with HAPs $\left(40 \mu \mathrm{g} \mathrm{mL}{ }^{-1}\right)$ for $24 \mathrm{~h}$, total RNA was extracted using Trizol reagent. Then, $2 \mu \mathrm{g}$ of RNA was performed to reverse transcriptase reaction using the RevertAid first strand cDNA synthesis kit. The PCR profile began with $10 \mathrm{~min}$ at $95^{\circ} \mathrm{C}$, followed by 40 cycles of $15 \mathrm{~s}$ at $95^{\circ} \mathrm{C}$ and $1 \mathrm{~min}$ at $60^{\circ} \mathrm{C}$, and later followed by the melting curve test. The primer sequences are listed in Table 1.

\section{DNA damage assay}

The DNA damage assay was performed according to literature. ${ }^{24}$ Cells $\left(6 \times 10^{6}\right.$ cells per well) were incubated in the presence or absence of HAPs $\left(40 \mu \mathrm{g} \mathrm{mL}^{-1}\right)$ for $24 \mathrm{~h}$. The cellular DNA damage was analyzed by a single cell gel electrophoresis (SCGE), also known as comet assay. Cellular DNA damage could be visualized under fluorescence microscope after staining with a fluorescent DNA-binding dye EB. Olive tail moment (OTM), the tail length and the percentage of DNA in the tail (tail DNA\%) were used to evaluate the extent of DNA damage of cells.

\section{Statistical analysis}

All results were confirmed in at least three separate experiments. Data are expressed as mean \pm standard deviation (SD). A one-way ANOVA was used for multiple comparisons. A value of $p$ less than 0.05 was considered significant.

\section{Results}

\section{Characterizations of HAPs}

The particle size and morphology of HAPs were observed under a TEM microscope. The sample is composed of nanorods with lengths of $\sim 80 \mathrm{~nm}$ and diameters of $\sim 20 \mathrm{~nm}$ (aspect ratios of 4) (Fig. 1A). The composition of HAPs was detected by XRD (Fig. 1B), and the diffraction peaks of sample can be well indexed to hexagonal phase hydroxyapatite (JCPDS no. 09-0432). The dispersibility of HAPs in medium was determined by DLS, indicating that the HAPs may be aggregated when they were added into cell culture medium (Fig. 1C). Fig. 1D shows the PL excitation and emission spectra of the HAPs. The excitation spectrum mainly exhibits a broad band from 280 to $400 \mathrm{~nm}$ with a maximum at $349 \mathrm{~nm}$. Under excitation at $349 \mathrm{~nm}$, the emission spectrum consists of an intense broad band from $350 \mathrm{~nm}$ to $600 \mathrm{~nm}$ (centered at $433 \mathrm{~nm}$ ), which exhibits a blue emission.

\section{Effect of HAPs on cell viability and apoptosis}

As shown in Fig. 2A, after the treatment with HAPs, the viability of MC3T3-E1 cells was significantly decreased in dose- and time-dependent manners. Fig. $2 \mathrm{~B}$ and $\mathrm{C}$ shows that the apoptotic rate of MC3T3-E1 cells was only $7.89 \%$ in control group. After being incubated with $40 \mu \mathrm{g} \mathrm{mL}{ }^{-1}$ of HAPs for $24 \mathrm{~h}$, the apoptotic rate of cells was increased significantly to $34.97 \%$.

\section{Cellular uptake, endocytosis and intracellular localization of HAPs}

As indicated in Fig. 3A and B, after cells were treated with 10, 20, 30 , and $40 \mu \mathrm{g} \mathrm{mL}^{-1}$ of HAPs for $2,4,6$, and $12 \mathrm{~h}$, the scatter intensity sharply increased compared with that of control group. The results showed that HAPs were taken by MC3T3-E1 cells in dose- and time-dependent manners. The result of endocytosis

Table 1 Primer sequences used in this work

\begin{tabular}{lll}
\hline Gene & Forward primer $\left(5^{\prime}-3^{\prime}\right)$ & Reverse primer $\left(5^{\prime}-3^{\prime}\right)$ \\
\hline bax & CAAAGTAGAAGAGGGCAACCAC & AGGATGCGTCCAAGAA \\
bcl-2 & AATCCGTAGGAATCCCAACC & CGAGAAGAAGAGAGAATCACAGG \\
Caspase3 & GCAAGCCATCTCCTCATCAG & TGACTGGAAAGCCGAAACTC \\
GAPDH & GACTTGAACAGCAACTCCCAC & TCCACCACCCTGTTGCTGTA
\end{tabular}



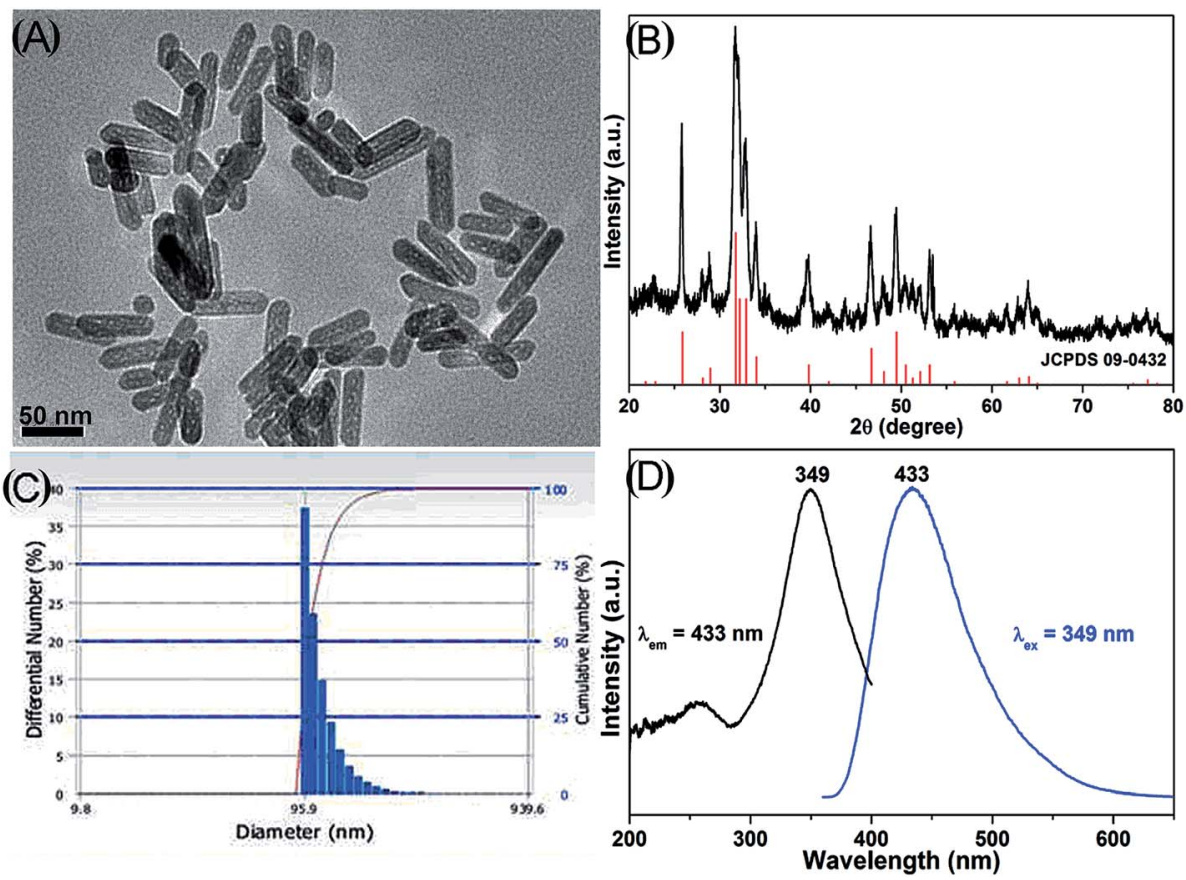

Fig. 1 Characterizations of HAPs. (A) TEM image. (B) XRD pattern. (C) Particle size distribution. (D) PL excitation and emission spectra of HAPs.
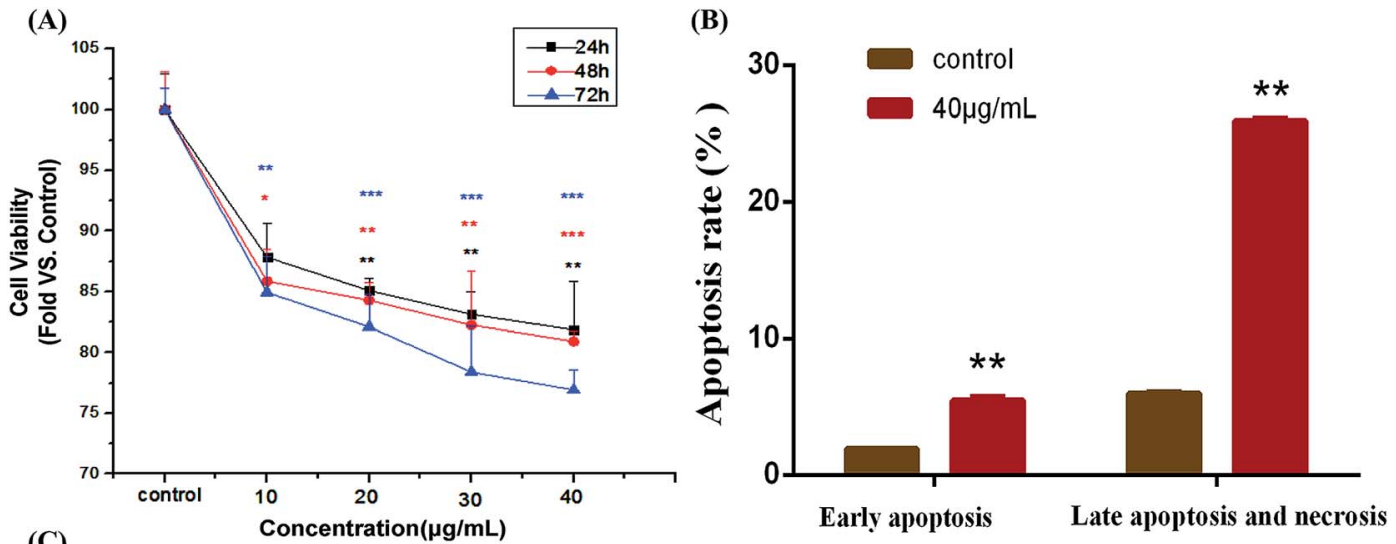

(C)
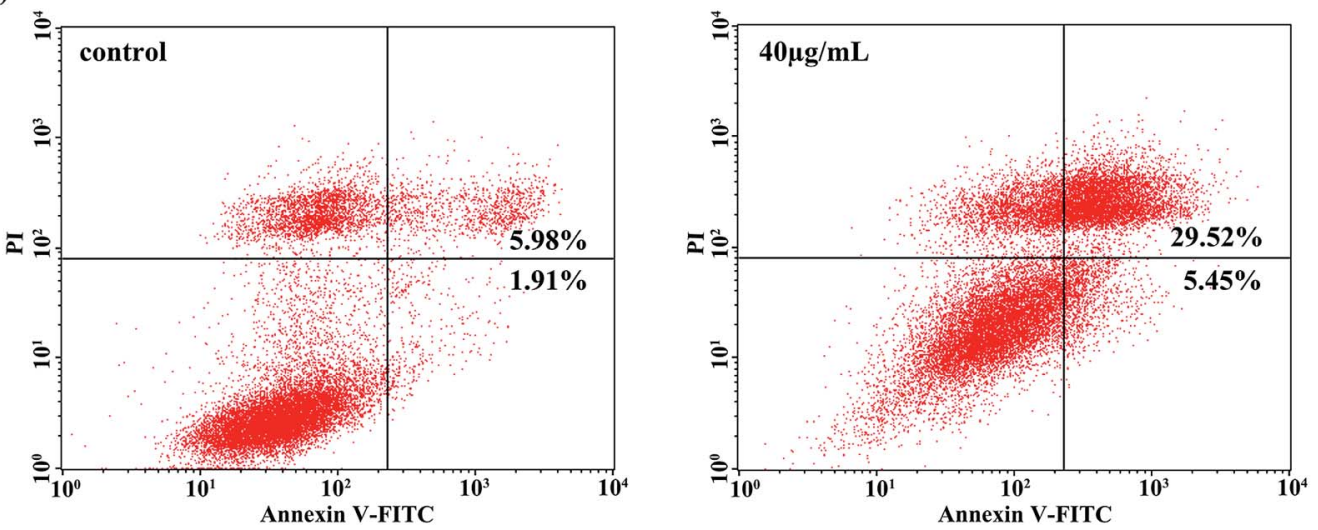

Fig. 2 (A) The cell viability of MC3T3-E1 cells after incubation with 10, 20, 30, and $40 \mu \mathrm{g} \mathrm{mL} \mathrm{L}^{-1}$ of HAPs for 24,48 , and $72 \mathrm{~h}(* p<0.05, * * p<0.01$, and $* * * p<0.001$ vs. control). (B and C) HAPs induced apoptosis in MC3T3-E1 cells. (B) Statistic analysis of apoptosis rate $(* * p<0.01$ vs. control). (C) Flow cytometric quantification of apoptotic cells upon exposure to $40 \mu \mathrm{g} \mathrm{mL} \mathrm{L}^{-1}$ of HAPs for $24 \mathrm{~h}$. 
(A)

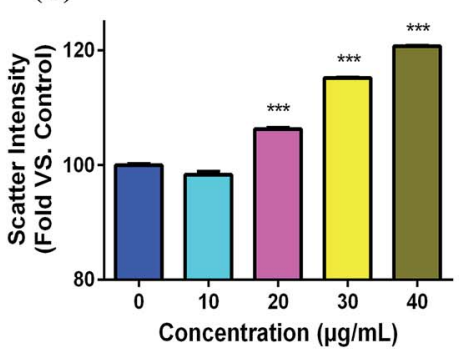

(D)
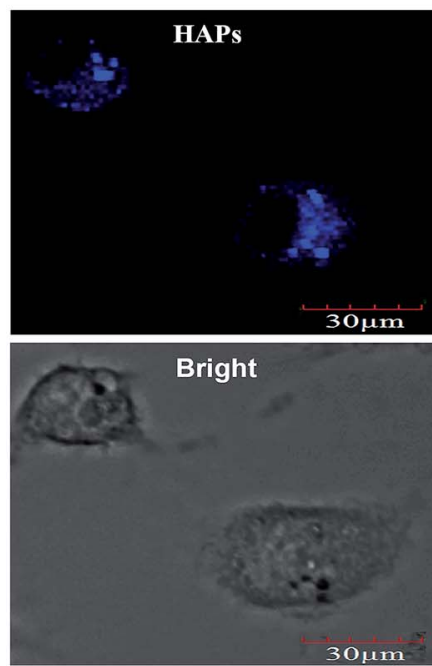

(B)

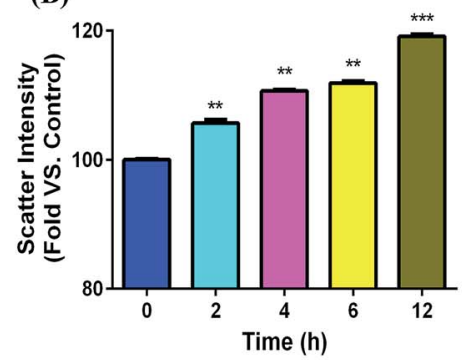

(C)
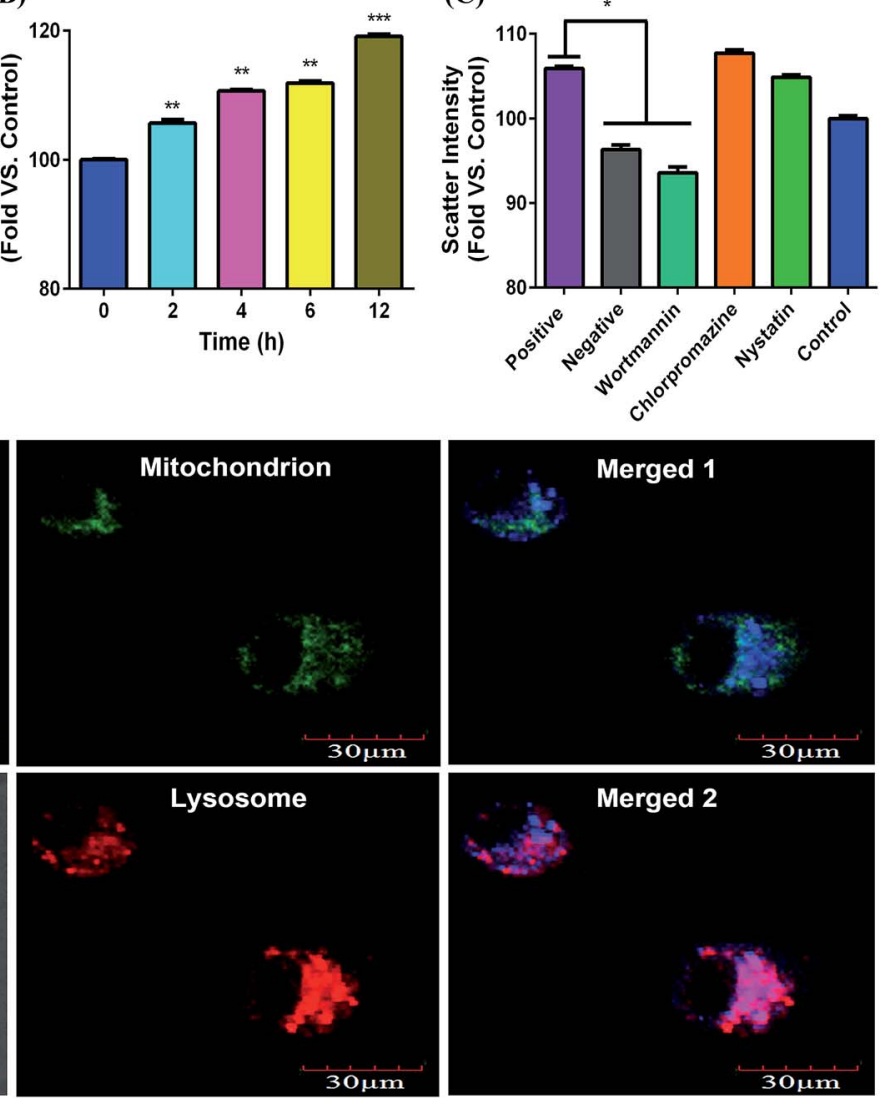
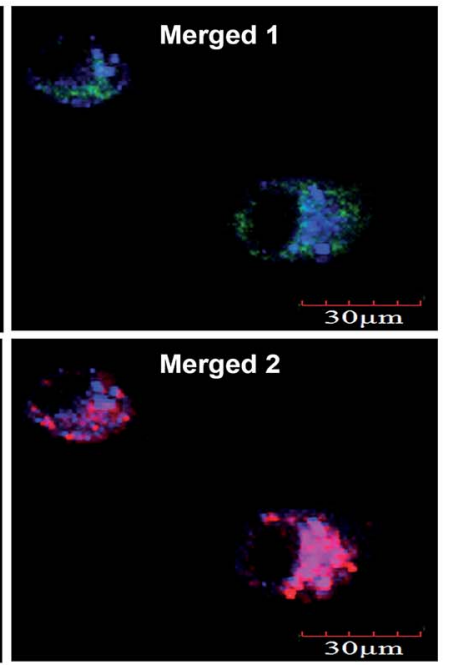

Fig. 3 Cellular uptake, endocytosis mechanism and intracellular localization of HAPs. (A) The cells were incubated with different concentrations of HAPs for $24 \mathrm{~h}$. (B) The cells were incubated with HAPs $\left(40 \mu \mathrm{g} \mathrm{mL}^{-1}\right)$ for 2, 4, 6, and $12 \mathrm{~h}$. (C) The endocytosis mechanism of HAPs into MC3T3E1 cells in the presence of different endocytosis inhibitors $(* p<0.05, * *<0.01$, and $* * * p<0.001$ vs. control). (D) Subcellular localization of HAPs in MC3T3-E1 cells using laser scanning confocal microscopy. The merged image 1 was HAPs and mitochondria. The merged image 2 was HAPs and lysosome. Bar: $30 \mu \mathrm{m}$.

mechanism from Fig. 3C showed that the scatter intensity of the macropinocytosis inhibitor (wortmannin) group led to a $12.5 \%$ decrease compared to that of positive group $\left(37^{\circ} \mathrm{C}\right)$, indicating that HAPs enter into cells through macropinocytosis pathway. To further ascertain the intracellular localization of HAPs in MC3T3-E1 cells, Lyso-Tracker and Mito-Tracker were used to label lysosome and mitochondrion, respectively. As shown in Fig. 3D, the blue fluorescence of HAPs overlapped with the red fluorescence of Lyso-Tracker mostly, but only a little with green fluorescence of Mito-Tracker. The result demonstrated that the HAPs were primarily distributed in lysosome.

\section{Measurement of ROS generation}

As shown in Fig. 4A, ROS level in MC3T3-E1 cells has an approximately 1.63-, 1.55-, 1.51-, and 1.48-fold increase compared with the control group after 10, 20, 30, and $40 \mu \mathrm{g}$ $\mathrm{mL}^{-1}$ of HAPs treatment for $24 \mathrm{~h}$. These results were also further confirmed by fluorescent microscope. As shown in Fig. 4B, when MC3T3-E1 cells were exposed to $40 \mu \mathrm{g} \mathrm{mL} \mathrm{m}^{-1}$ of HAPs for $24 \mathrm{~h}$, the fluorescence intensity increased. However, when MC3T3-E1 were pretreated with $5 \mathrm{mM} \mathrm{N}$-acetylcysteine (NAC) for $1 \mathrm{~h}$ prior to $12 \mathrm{~h}$ treatment with 10, 20, 30, $40 \mu \mathrm{g} \mathrm{mL}$ of HAPs, the inhibition of cell proliferation induced by HAPs turned to decrease (Fig. 4C).

\section{Effects of HAPs on SOD and GSH-Px activity}

The activities of antioxidant enzymes SOD and GSH-Px decreased in HAPs treated cells compared to control cells. As shown Fig. 4D and E, HAPs at a concentration of $10 \mu \mathrm{g} \mathrm{mL}$ caused a $72 \%$ decrease in SOD activity. $40 \mu \mathrm{g} \mathrm{mL}^{-1}$ of HAPs also induced a marked decrease in GSH-Px activity after $24 \mathrm{~h}$ treatment.

\section{Effects of HAPs on lysosomal damage and cathepsin B activity}

As shown in Fig. 5A, after treatment with HAPs, the fluorescence intensity of treated cells was significantly decreased than that of control group, indicating lysosomal rupture. Meanwhile, cathepsin B was notably released from the lysosomes of MC3T3E1 cells after incubation with $40 \mu \mathrm{g} \mathrm{mL}^{-1}$ HAPs (Fig. 5B).

\section{Measurement of intracellular MMP}

As shown in Fig. 5C, 10 and $20 \mu \mathrm{g} \mathrm{mL}^{-1}$ of HAPs have no effect on intracellular MMP, but 30 and $40 \mu \mathrm{g} \mathrm{mL} \mathrm{m}^{-1}$ of HAPs induced 
(A)

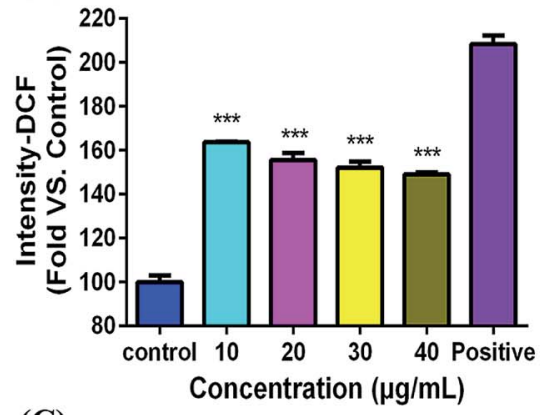

(C)

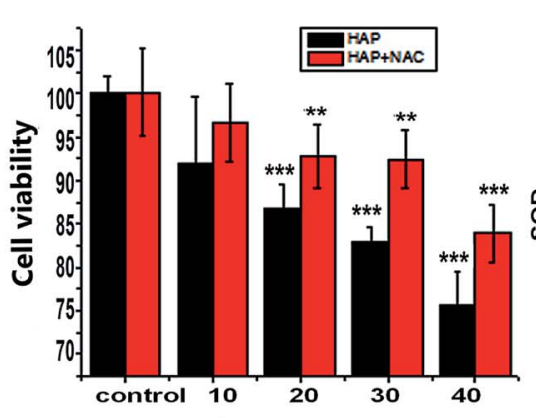

(B)

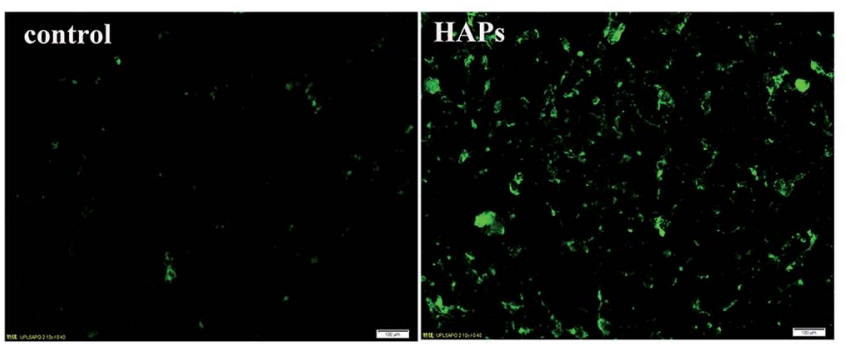

(E)
(D)

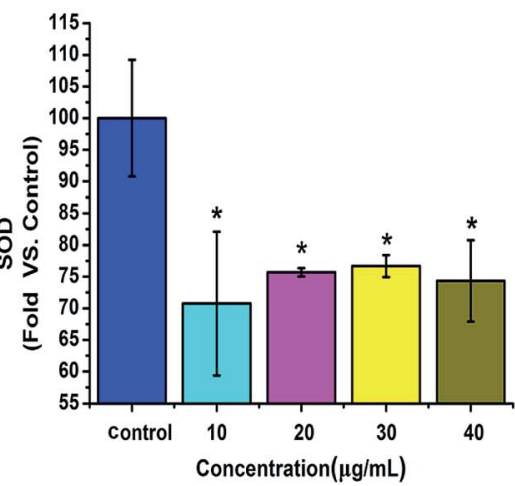

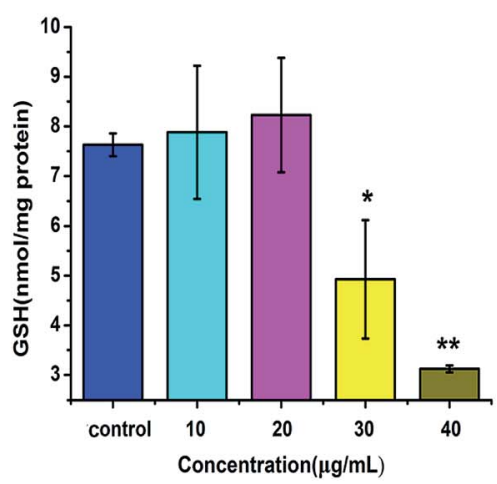

Fig. 4 Oxidative stress-induced by HAPs in MC3T3-E1 cells. (A) The relative fluorescence intensity of DCF measured by flow cytometer after MC3T3-E1 cells were exposed to different concentrations HAPs for $24 \mathrm{~h}$. (B) The morphological images of the cells stained by DCFH-DA were observed under fluorescence microscope after cells were exposed to $40 \mu \mathrm{g} \mathrm{mL}^{-1}$ of HAPs for $24 \mathrm{~h}$. (C) The protective effect of NAC against HAPs-induced inhibition of cell proliferation. (D) SOD and (E) GSH-Px activities after treatment with different concentrations of HAPs (10, 20, 30, and $\left.40 \mu \mathrm{g} \mathrm{mL}^{-1}\right)$ for $24 \mathrm{~h}(* p<0.05, * * p<0.01$, and $* * * p<0.001 \mathrm{vs}$. control).

depolarization of the mitochondrial inner membrane and resulted in the loss of MMP.

\section{Effect of HAPs on apoptosis-related genes}

The mRNA levels of the apoptosis-related genes, including bcl2, bax and caspase 3 after treatment by HAPs in MC3T3-E1 cells were shown in Fig. 5D. It can be seen that bcl-2 mRNA level was significantly suppressed by HAPs. But the bax and caspase 3 mRNA levels in MC3T3-E1 cells were obviously increased in contrast with control group. The mRNA levels of bax and caspase3 were about 2.1- and 1.6-fold higher than that of control group, respectively.

\section{DNA damage induced by HAPs}

As shown in Fig. 5E and F, compared with control cells, $40 \mu \mathrm{g}$ $\mathrm{mL}^{-1}$ HAPs induced prominent DNA damage, confirmed by tail length (87.33 vs. 6), tail DNA\% (47.20 vs. 6.20), and olive tail moment (25.70 vs. 0.93).

\section{Discussion}

The interaction between HAPs and the biological system has a close relationship with the physico-chemical properties of particles. As recommended for toxicological evaluation, the physico-chemical properties of the HAPs were also important. The HAPs used in the experiment were rod-like particles with aspect ratios of 4 . The XRD pattern of HAPs demonstrated the pure hexagonal phase of HAPs was formed without impurity phase detecting (Fig. 1). To clarify the effect of HAPs on MC3T3E1 cells, we first tested cell vitality of MC3T3-E1 cells by MTT assay following exposure to varying concentrations of HAPs. The results revealed that HAPs exerted significant cytotoxicity and inhibited the proliferation of MC3T3-E1 cells in dose- and timedependent manners (Fig. 2A). Induction of apoptosis or necrosis may account for the anti-proliferation effect. From the analysis of annexin V-FITC/PI staining assay by flow cytometry showed that the apoptotic rate of MC3T3-E1 cells treated with HAPs for $24 \mathrm{~h}$ was increased significantly, indicating HAPs could induce the apoptosis of MC3T3-E1 cells (Fig. 2B and C).

As we know, the degree of cell damage may be closely associated with the uptake and accumulation of the nanoparticles in cells. ${ }^{25}$ It was also reported that shape, size and surface charge could influence the cellular uptake behavior and mechanism of nanoparticles. ${ }^{26-28}$ The HAPs used in the experiment were $50 \mathrm{~nm}$. HAPs could be uptaken by MC3T3-E1 in a dose- and time-dependent manners (Fig. 3A and B). It is well known that the smaller and larger particles enter into cells via endocytosis and phagocytosis, respectively. ${ }^{29}$ The entry mechanism of various nanoparticles which has been reported as endocytosis was involved in clathrin, caveolae and pinocytosis. ${ }^{30}$ In order to discriminate the possible endocytosis pathway, several specific inhibitors of endocytosis routes included chlorpromazine, 
(A)

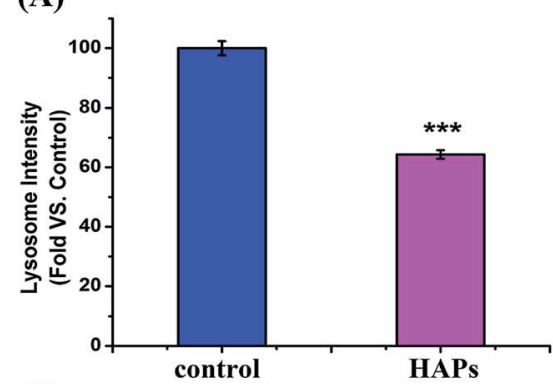

(C)

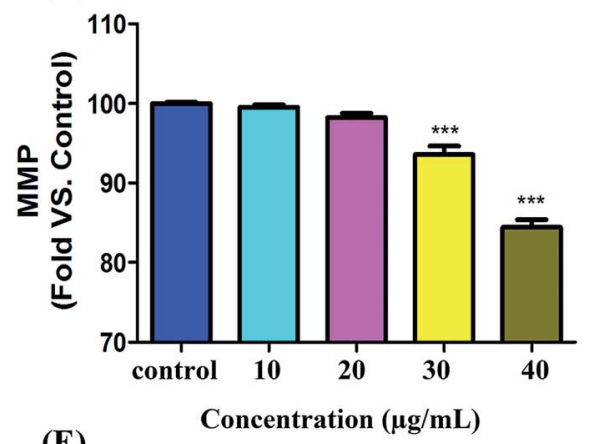

(E)

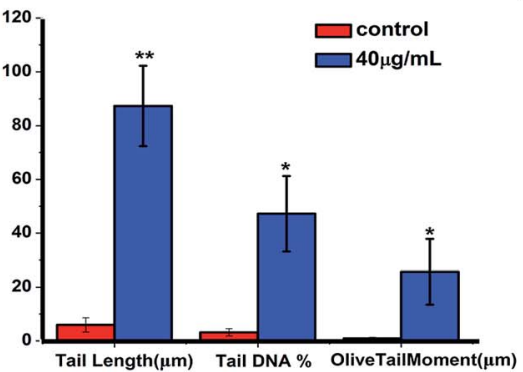

(B)

(D)
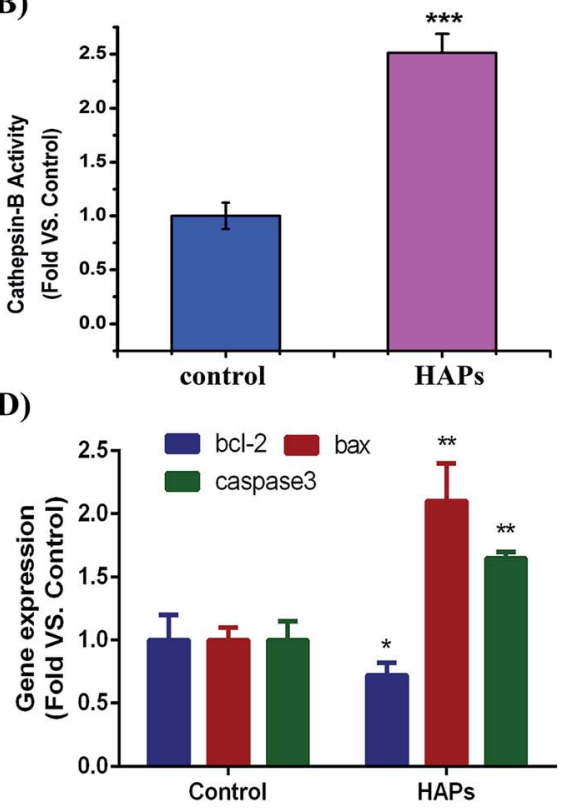

(F)

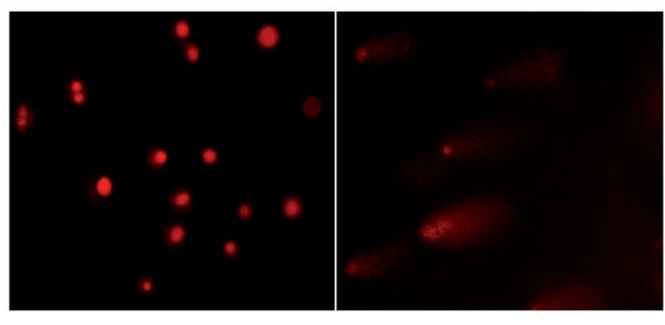

Fig. 5 Apoptosis mechanism of MC3T3-E1 cells induced by HAPs. (A) The relative fluorescence intensity of AO measured by flow cytometer. (B) The cathepsin B activity of MC3T3-E1 exposed to $40 \mu \mathrm{g} \mathrm{mL} \mathrm{L}^{-1}$ of HAPs for $24 \mathrm{~h}$. (C) Measurement of MMP in MC3T3-E1 cells after treatment with $10,20,30$, and $40 \mu \mathrm{g} \mathrm{mL} \mathrm{m}^{-1} \mathrm{HAPs}$ for $24 \mathrm{~h}$. (D) The expression of apoptosis specific genes. (E and F) DNA damage caused by $40 \mu \mathrm{g} \mathrm{mL} \mathrm{m}^{-1} \mathrm{HAPs}_{\mathrm{n}}$ MC3T3-E1 cells for $24 \mathrm{~h}$. (E) DNA damage are evaluated by tail DNA\%, tail length and olive tail moment $(* p<0.05, * * p<0.01$, and $* * * p<0.001$ vs. control). (F) Representative images of the comet assay for MC3T3-E1 cells.

nystatin and wortmannin were used. Chlorpromazine is a known inhibitor of clathrin-mediated endocytosis, which induces dissociation of the clathrin lattice. Nystatin is a sterolbinding agent which disrupts caveolar integrity. Wortmannin as a potent phosphatidylinositol 3-kinase inhibitor is useful for inhibiting macropinocytosis..$^{31}$ Our results indicated that HAPs enter into cells via an energy-dependent macropinocytosis endocytosis pathway (Fig. 3C). To further confirm the subcellular localization of HAPs in cells, Lyso-Tracker Red and MitoTracker Green as mitochondrial and lysosome indicators were used in our work. From the analysis of co-localization image, HAPs were found mainly localized in lysosome, slightly localized in mitochondria, and not in the cell nucleus (Fig. 3D).

It was reported that nanomaterials could provoke oxidative stress. $^{32,33}$ Oxidative stress, where there is an imbalance between ROS and the cell's antioxidant capacity, is one of the classical stress response mechanisms, also plays an important role in the mechanism of the cell injury. ${ }^{34}$ It is well known that ROS, SOD and GSH are three important biochemical and physiological indexes of oxidative stress. ROS at high level could cause nuclear DNA proteins, carbohydrates and lipids damage. SOD, as one of enzymatic scavengers of ROS, can decrease the accumulation of ROS and prevent the oxidative injury. So the activity level of SOD is closely related to the antioxidative damage ability. ${ }^{35} \mathrm{GSH}$, as an important antioxidant, is capable of preventing damage to important cellular components caused by ROS. ${ }^{36}$ Thus, preserving the GSH-mediated antioxidant defense is critical for cell survival. SOD can catalyze the dismutation of superoxide into $\mathrm{H}_{2} \mathrm{O}_{2}$, and then by GSH-Px and catalase (CAT) to decompose $\mathrm{H}_{2} \mathrm{O}_{2}$ into $\mathrm{H}_{2} \mathrm{O}$. In this study, the augmentation of ROS was found in MC3T3-E1 of HAPs treated group (Fig. 4A and B). Meanwhile, the activities of antioxidant enzymes SOD and GSH-Px were decreased in HAPs treated cells, which corresponds with the increase in apoptotic cells (Fig. 4C and D). Moreover, ROS scavenger NAC was used for further study. MTT results showed that when cells were pre-treated with NAC, the cell viability increased observably in HAPs-treated group, indicating NAC can reduce the cell damage by HAPs. All results 
demonstrated that HAPs might induce the apoptosis of MC3T3E1 cells by enhancement of intracellular ROS generation, and affect the oxidant-antioxidant balance.

There are some different mechanisms involved in toxicity effects of nanomaterials. Numerous studies confirmed that nanomaterials may induce apoptosis, necrosis or inflammation by oxidative stress. ${ }^{37}$ Oxidative stress as an important mediator of cytotoxicity, can leads to very different outcomes, such as injury of lysosome integrity as well as potential compensatory responses, mitochondrial dysfunction, DNA oxidative damage and so on. ${ }^{38}$ Recently some researches also shown that there are two major intrinsic apoptotic pathways: mitochondria and lysosome pathways. ${ }^{39,40}$ The mitochondrial pathway is mediated by bcl-2 family proteins, which regulate the release of cytochrome c from the mitochondria into the cytosol followed by caspase 3 activation. bcl-2 directly control the permeability of the outer mitochondrial membrane, whereas bax induces the opening of membrane pore. ${ }^{41}$ Results from Real-time PCR demonstrated that the HAPs down-regulated the level of bcl-2, up-regulated the level of bax and activate caspase3 (Fig. 5D). This could be concluded that HAPs activates the mitochondria apoptotic pathway, which is characterized by modulation of bax and bcl-2 expressions, and loss of MMP (Fig. 5C). With the exception of its important role in degradation of proteins, the lysosome is now also recognized as a key factor of integration of different apoptotic stimuli. ${ }^{\mathbf{4 2 , 4 3}}$ Studies suggest that oxidative stress involved in lysosomal related apoptotic cascades. $^{\mathbf{4 4 , 4 5}}$ Many studies have demonstrated that lysosomal permeabilization was a key factor in the process of cell death, consequently facilitated the release of lysosomal enzymes into the cytoplasm, such as cathepsin B, a lysosomal cysteine protease, which is a candidate for an apoptotic mediator originating from acidic vesicles. Yan et al. reported that cathepsin B played an essential role in tumor necrosis factor- (TNF- $\alpha$ )-induced apoptosis in vitro and in vivo. ${ }^{\mathbf{4 6}}$ Due to the importance of lysosomal destabilization in the initiation of the apoptotic pathway, we examined the potential role of HAPs in inducing LMP. Our study clearly showed HAPs caused a significant increase of LMP (Fig. 5A) and the activity of cathepsin $\mathrm{B}$ (Fig. 5B). The results suggest that lysosomal membrane damage may induce cathepsin $B$ release which contributed significantly to HAPs-mediated apoptosis in MC3T3E1 cells. In addition, it was reported that endogenous ROS is the important source of spontaneous damage to DNA. ${ }^{47}$ The alkaline comet assay was recommended for assessing the genotoxicity of materials. ${ }^{48}$ We found that HAPs could cause DNA lesions (Fig. 5E and F). Therefore, we concluded that ROS-related DNA lesions was also a important factor of cell apoptosis caused by HAPs.

Together, this work proposed a mechanism of the MC3T3-E1 cells apoptosis induced by HAPs. The HAPs were uptaken into MC3T3-E1 cells through an macropinocytosis endocytosis pathway and localized in lysosome. HAPs induced oxidative stress, caused the imbalance of ROS and the cell's antioxidant capacity. On one hand, the oxidative stress induced lysosomal rupture, cathepsin $\mathrm{B}$ release, which is a pathway mediating apoptosis. On the other hand, oxidative stress induced a mitochondria-dependent apoptosis pathway via modulation of bax

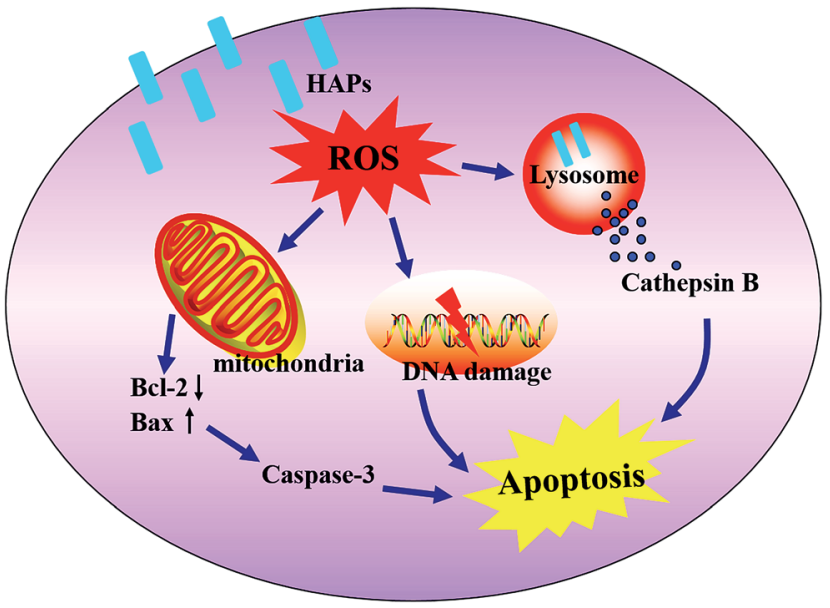

Fig. 6 The mechanism of apoptosis of MC3T3-E1 induced by HAPS.

and bcl-2 expressions, disruption of MMP, activation of caspase3. In addition, HAPs also caused DNA lesions (Fig. 6).

\section{Conclusion}

In conclusion, the results showed that HAPs could induce apoptosis in MC3T3-E1 cells via oxidative stress. HAPs induced ROS generation and led to damage to cellular components. The overproduction of ROS not only induced lysosomal rupture, but also damaged the mitochondria and DNA. Our study will provide some valuable data for biomedical applications of HAPs in the future.

\section{Conflict of interest}

The authors declare that no competing interests exist.

\section{Acknowledgements}

This work was supported in part by Chinese Natural Science Foundation Project (21271059, 81200078, 21301046, 51302062), "Three Three Three" Talents Project of Hebei Province (A201401002), Research Fund for the Doctoral Program of Higher Education of China (20131301120004), Hebei Province "Hundred Talents Program" (BR2-202), Key Program of Hebei Education Department (ZD2015031), China Postdoctoral Science Foundation Funded Project (2013M530119, 2014T70226), Training Program for Innovative Research Team and Leading Talent in Hebei Province University (LJRC024). The Second Batch of Top Youth Talent Support Program of Hebei Province, Distinguished Young Scholars Fund of Hebei University (2015JQ04).

\section{References}

1 N. Tamai, A. Myoui, T. Tomita, T. Nakase, J. Tanaka, T. Ochi and H. Yoshikawa, J. Biomed. Mater. Res., 2002, 59, 110-117.

2 D. A. Wahl and J. T. Czernuszka, Eur. Cells Mater., 2006, 28, 43-56. 
3 B. S. Kim, J. S. Kim, Y. S. Chung, Y. W. Sin, K. H. Ryu, J. Lee and H. K. You, J. Biomed. Mater. Res., Part A, 2013, 101, 15501558.

4 H. Cao, L. Zhang, H. Zheng and Z. Wang, J. Phys. Chem. C, 2010, 114, 18352-18357.

5 V. Uskoković and D. P. Uskoković, J. Biomed. Mater. Res., Part $B, 2011,96,152-191$.

6 H. W. Kim, J. H. Song and H. E. Kim, J. Biomed. Mater. Res., Part A, 2006, 79, 698-705.

7 D. Bhuiyan, M. J. Jablonsky, I. Kolesov, J. Middleton, T. M. Wick and R. Tannenbaum, Acta Biomater., 2015, 15, 181-190.

8 C. M. Curtin, G. M. Cunniffe, F. G. Lyons, K. Bessho, G. R. Dickson, G. P. Duffy and F. J. O'Brien, Adv. Mater., 2012, 24, 749-754.

9 N. S. Remya, S. Syama, V. Gayathri, H. K. Varma and P. V. Mohanan, Colloids Surf., B, 2014, 117, 389-397.

10 C. Wang, D. Liu, C. Zhang, J. Sun, W. Feng, X.-J. Liang, S. Wang and J. Zhang, ACS Appl. Mater. Interfaces, 2016, 8, 11262-11271.

11 A. Doostmohammadi, A. Monshi, R. Salehi, M. H. Fathi, E. Seyedjafari, A. Shafiee and M. Soleimani, Biomed. Pap., 2011, 155, 323-326.

12 J. S. Sun, F. H. Lin, T. Y. Hung, Y. H. Tsuang, W. H. Chang and H. C. Liu, J. Biomed. Mater. Res., 1999, 45, 311-321.

13 L. Chen, J. M. Mccrate, J. C. Lee and H. Li, Nanotechnology, 2011, 22, 105708.

14 L. Wang, G. Zhou, H. Liu, X. Niu, J. Han, L. Zheng and Y. Fan, Nanoscale, 2012, 4, 2894-2899.

15 M. Suda, K. Tanaka, K. Natsui, T. Usui, I. Tanaka, M. Fukushima, C. Shigeno, J. Konishi, S. Narumiya, A. Ichikawa and N. Nakao, Endocrinology, 1996, 137, 16981705.

16 C. Zhang, J. Yang, Z. Quan, P. Yang, C. Li, Z. Hou and J. Lin, Cryst. Growth Des., 2009, 9, 2725-2733.

17 D. Liu, C. Yi, D. Zhang, J. Zhang and M. Yang, ACS Nano, 2010, 4, 2185-2195.

18 J. P. Aubry, A. Blaecke, S. Lecoanet-Henchoz, P. Jeannin, N. Herbault, G. Caron, V. Moine and J. Y. Bonnefoy, Cytometry, 1999, 37, 197-204.

19 S. Chen, Y. Hou, G. Cheng, C. Zhang, S. Wang and J. Zhang, Biol. Trace Elem. Res., 2013, 154, 156-166.

20 S. Chen, C. Zhang, G. Jia, J. Duan, S. Wang and J. Zhang, Mater. Sci. Eng., C, 2014, 43, 330-342.

21 S. Bhattacharjee, D. Ershov, M. A. Islam, A. M. Kampfer, K. A. Maslowska, J. van der Gucht, G. M. Alink, A. T. M. Marcelis, H. Zuilhofa and L. M. C. M. Rietjens, RSC Adv., 2014, 4, 19321-19330.

22 K. Ge, W. Sun, S. Zhang, S. Wang, G. Jia, C. Zhang and J. Zhang, RSC Adv., 2016, 6, 21725-21734.

23 T. Sato, T. Machida, S. Takahashi, K. Murase, Y. Kawano, T. Hayashi, S. Iyama, K. Takada, K. Kuribayashi, Y. Sato, M. Kobune, R. Takimoto, T. Matsunaga, J. Kato and Y. Niitsu, J. Immunol., 2008, 181, 197-207.
24 S. Nunes Rda, V. F. Kahl, S. Sarmento Mda, M. F. Richter, J. A. Abin-Carriquiry, M. M. Martinez, B. Ferraz Ade and J. Da Silva, Phytother. Res., 2013, 27, 1495-1501.

25 Y. H. Ma, C. P. Huang, J. S. Tsai, M. Y. Shen, Y. K. Li and L. Y. Lin, Toxicol. Lett., 2011, 207, 258-269.

26 L. Hu, Z. Mao and C. Gao, J. Mater. Chem., 2009, 19, 31083115.

27 Y. Cai, Y. Liu, W. Yan, Q. Hu, J. Tao, M. Zhang, Z. Shi and R. Tang, J. Mater. Chem., 2007, 17, 3780-3787.

28 S. E. Gratton, P. A. Ropp, P. D. Pohlhaus, J. C. Luft, V. J. Madden, M. E. Napier and J. M. Desimone, Proc. Natl. Acad. Sci. U. S. A., 2008, 105, 11613-11618.

29 S. D. Conner and S. L. Schmid, Nature, 2003, 422, 37-44.

30 Y. Jin, S. Chen, J. Duan, G. Jia and J. Zhang, J. Inorg. Biochem., 2015, 146, 28-36.

31 C. Greulich, J. Diendorf, T. Simon, G. Eggeler, M. Epple and M. Köller, Acta Biomater., 2011, 7, 347-354.

32 Y. J. Kim, M. Yu, H. O. Park and S. I. Yang, Mol. Cell. Toxicol., 2010, 6, 336-343.

33 M. I. Setyawati, C. Y. Tay and D. T. Leong, Biomaterials, 2013, 34, 10133-10142.

34 I. Passagne, M. Morille, M. Rousset, I. Pujalté and B. L'azou, Toxicology, 2012, 299, 112-124.

35 P. Xu, J. Xu, S. Liu and Z. Yang, J. Hazard. Mater., 2012, 241, 279-286.

36 W. Lin, Y. Huang, X. Zhou and Y. Ma, Toxicol. Appl. Pharmacol., 2006, 217, 252-259.

37 H. Turkez, M. I. Yousef, E. Sönmez, B. Togar, F. Bakan, P. Sozio and A. D. Stefano, J. Appl. Toxicol., 2014, 34, 373-379.

38 T. Kurz, A. Terman, B. Gustafsson and U. T. Brunk, Biochim. Biophys. Acta, 2008, 1780, 1291-1303.

39 V. Stoka, B. Turk, S. L. Schendel, T. H. Kim, T. Cirman, S. J. Snipas, L. M. Ellerby, D. Bredesen, H. Freeze, M. Abrahamson, D. Brömme, S. Krajewski, J. C. Reed, X. M. Yin, V. Turk and G. S. Salvesen, J. Biol. Chem., 2001, 276, 3149-3157.

40 S. Fulda, E. Meyer, C. Friesen, S. A. Susin, G. Kroemer and K. M. Debatin, Oncogene, 2001, 20, 1063-1075.

41 E. Z. Bagci, Y. Vodovotz, T. R. Billiar, G. B. Ermentrout and I. Bahar, Biophys. J., 2006, 90, 1546-1559.

42 S. Aits and M. Jaattela, J. Cell Sci., 2013, 126, 1905-1912.

43 U. Repnik, V. Stoka, V. Turk and B. Turk, Biochim. Biophys. Acta, 2012, 1824, 22-33.

44 G. Hristov, T. Marttila, C. Durand, B. Niesler, G. A. Rappold and A. Marchini, Hum. Mol. Genet., 2014, 23, 1619-1630.

45 C. O. Eno, G. Zhao, A. Venkatanarayan, B. Wang, E. R. Flores and C. Li, Free Radical Biol. Med., 2013, 65, 26-37.

46 B. Yan, W. Wang, L. Chen, M. Bi, Y. Lu, B. Li and B. Yang, World J. Gastroenterol., 2009, 15, 1231-1236.

47 S. Kim and D. Y. Ryu, J. Appl. Toxicol., 2013, 33, 78-89.

48 V. Opačić-Galić, V. Petrović, S. Zivković, V. Jokanović, B. Nikolić, J. Knežević-Vukčević and D. Mitić-Ćulafić, Int. Endod. J., 2013, 6, 506-516. 